www.jmscr.igmpublication.org Impact Factor 5.244

Index Copernicus Value: 5.88 ISSN (e)-2347-176x ISSN (p) 2455-0450 crossref DOI:_http://dx.doi.org/10.18535/jmscr/v4i6.73

\title{
Serum Iron and Total Iron Binding Capacity in Preeclampsia
}

\author{
Authors \\ A. P. Moholkar ${ }^{1}$, K. N. Pujari², M. P. Bankar ${ }^{3}$, S. P. Jadkar \\ ${ }^{1}$ Lecturer, Department of Biochemistry, Yogita Dental College, Khed \\ ${ }^{2}$ Associate Professor, Department of Biochemistry, R.C.S.M. Govt. Medical College, Kolhapur \\ ${ }^{3}$ Associate professor, Department of Biochemistry, B J Medical College, Pune \\ ${ }^{4} \mathrm{Ph} \mathrm{D}$ student, Department of Biochemistry, Govt. Medical College, Miraj \\ Corresponding Author \\ Dr Karan N. Pujari \\ Associate professor, Department of Biochemistry, \\ R.C.S.M. Govt. Medical College, Kolhapur (Maharashtra, India) \\ Email: pujari_karyappa@yahoo.in
}

\begin{abstract}
Preeclampsia (PE) is a pregnancy-specific condition that increases maternal and infant mortality and morbidity. Exact etiology of preeclampsia is still not known but certain hypothesis suggest it may be associated with an increased vascular resistance of uterine artery and decrease in perfusion of placenta. It has been suggested that lipid peroxidation plays an important role in the etiology of preeclampsia. Iron and hematin proteins play important roles as catalysts of lipid peroxidation in tissues. The aim of study was to estimate and compare serum iron and total iron binding capacity in preeclamptic women and normal pregnant women. Study was conducted in Government Medical Hospital Miraj with 120 subjects. The studied population consisted: group I (40 normal pregnant women) and group II (80 pregnant women with preeclampsia). Serum iron and total iron binding capacity values were measured by ferrozine method. We found significantly high serum iron and significantly low total iron binding capacity in preeclamptic women as compare to normal pregnant women $(p<0.001)$. So elevated serum iron and decreased total iron binding capacity may play an important role in the pathogenesis of preeclampsia.

Key words: Iron, Preeclampsia, Total iron binding capacity
\end{abstract}

\section{Introduction}

Preeclampsia (PE) is a pregnancy-specific condition that increases maternal and infant mortality and morbidity (1). In the mother, preeclampsia may cause premature cardiovascular disease, such as chronic hypertension, ischemic heart disease, and stroke, later in life, while children born after preeclamptic pregnancies and who are relatively small at birth, have an increased risk of stroke, coronary heart disease, and metabolic syndrome in adult life ${ }^{(2)}$. It is diagnosed by new-onset increased blood pressure and proteinuria during second or third trimester of gestation $^{(1)}$.

Other complications of preeclampsia includes premature delivery resulting in the need of intensive care admissions for neonates, intracranial hemorrhage, acute renal tubular necrosis, heart failure, pulmonary edema, hemolysis and increased liver enzymes ${ }^{(3)}$. Exact 
etiology of preeclampsia is still not known but certain hypothesis suggest it may be associated with an increased vascular resistance of uterine artery and decrease in perfusion of placenta ${ }^{(4)}$. It has been suggested that lipid peroxidation plays an important role in the etiology of preeclampsia. Iron and hematin proteins play important roles as catalysts of lipid peroxidation in tissues. Oxidative stress and increase iron levels in the maternal compartment in preeclampsia may be responsible for causing oxidative stress in placenta ${ }^{(5)}$.

The present study was planed to measure alterations in serum iron and total iron binding capacity (TIBC) in preeclamptic pregnancy and to compare with those in normal pregnancy.

\section{Materials and Methods}

Study was carried out in the department of Biochemistry Government Medical College and Hospital, Miraj, Maharashtra (India). Study protocol was approved by ethical committee of Government Medical College Miraj.

\section{Selection and Distribution of subjects}

Sample size: Study includes total 120 subjects with age above 18 years and classified into two groups.

Group I (Patients): Includes total 80 hypertensive pregnant women. These are classified into 2 groups.

- Mild preeclampsia: 40 as severe mild preeclamptic patient.

- Severe preeclampsia: 40 as severe preeclamptic patient.

Group II (control): Consist of 40 non hypertensive pregnant women individual matching in age with patients serve as control.
Controls were selected from those who are attaining OPD of Government Medical College and Hospital, Miraj.

\section{Sample (Blood) Collection}

Informed consent was obtained from all the participants. To avoid contamination plain tubes were washed with double distilled water and autoclaved previously. $2 \mathrm{ml}$ blood samples were withdrawn by using twenty gauze stainless still disposable needles attached to $5 \mathrm{ml}$ polythene disposable syringe from anticubital vein with aseptic precautions. Needle was removed and blood was collected in plain bulb.

Two hours after the collection of blood, the test tube with blood samples were centrifuged at 3000 R.P.M. for $5 \mathrm{~min}$. Serum was separated and stored in polythene tube with cork. Serum samples were preserved in freezer at $0-4^{\circ} \mathrm{C}$ until tested. The stored sera were used for Estimation of iron and total iron binding capacity (TIBC). Serum iron and TIBC were estimated by ferrozine method ${ }^{(6-}$ 8). The statistical tests included unpaired student's ' $t$ ' test and regression analysis for correlation coefficient.

\section{Observations and Results}

We observed significant increase $(\mathrm{P}<0.001)$ in serum iron level in patients with preeclampsia as compared to that of normal pregnant women. In mild cases of preeclampsia the mean iron level was less than that of severe preeclampsia (table 1). Where as we observed significant decrease in TIBC in patients as compared to control. In mild cases of preeclampsia the mean TIBC level was more than that of severe preeclampsia (table 1).

Table 1: Serum Iron and Total Iron Binding Capacity (TIBC) in subjects

\begin{tabular}{|l|c|c|}
\hline Subjects & $\begin{array}{c}\text { TIBC mmol/L } \\
\text { Mean } \pm \text { SD }\end{array}$ & $\begin{array}{c}\text { Iron mmol/L } \\
\text { Mean } \pm \text { SD }\end{array}$ \\
\hline $\begin{array}{l}\text { Preeclampsia (total) } \\
\text { Group I (n=80) }\end{array}$ & $16.33 \pm 4.375^{*}$ & $46.93 \pm 8.823^{*}$ \\
\hline $\begin{array}{l}\text { Mild Preeclampsia } \\
(\mathrm{n}=40)\end{array}$ & $20.46 \pm 1.074^{*}$ & $39.04 \pm 2.714^{*}$ \\
\hline Severe Preeclampsia $(\mathrm{n}=40)$ & $12.19 \pm 1.593^{*}$ & $54.82 \pm 4.758^{*}$ \\
\hline Control Group II $(\mathrm{n}=40)$ & $44.7 \pm 12.327$ & $23.87 \pm 5.855$ \\
\hline
\end{tabular}

$*_{\mathrm{p}}<0.001$, Highly Significant 


\section{Discussion}

We found significantly high serum iron and significant low TIBC in preeclampsia as compared to control. These results are in similar with Shakuntal Masti et al ${ }^{(9)}$, Rana M Hamed et al (3) and Rehab Mohamed et al ${ }^{(10)}$. This may be due to hemolysis caused by physical destruction of RBCs as a result of vasoapam ${ }^{(11)}$ and also due to decreased ability of transferring to bind with free iron in the circulation ${ }^{(12)}$.

Increased oxidative stress may play a role in the development of preeclampsia ${ }^{(9)}$. The balance between free radicals (pro-oxidants) and antioxidants shifted towards the pro-oxidants is known as oxidative stress ${ }^{(13)}$. Excess iron is postulated as causal factor in the oxidative stress that is in its radical form involved in pathogenesis of preeclampsia ${ }^{(9)}$.

In presence of free iron, hydrogen peroxide $\left(\mathrm{H}_{2} \mathrm{O}_{2}\right)$ is converted into the most reactive and damaging free radical that is hydroxyl radical $\left(\mathrm{OH}^{\bullet}\right)^{(14)}$

$$
\begin{aligned}
& \mathrm{Fe}^{++}+\mathrm{H}_{2} \mathrm{O}_{2} \longrightarrow \mathrm{Fe}^{+++}+\mathrm{OH}^{\bullet}+\mathrm{OH}^{-} \text {(Fenton reaction) } \\
& \mathrm{O}_{2}+\mathrm{H}_{2} \mathrm{O}_{2} \longrightarrow \mathrm{O}_{2}+\mathrm{OH}^{\bullet}+\mathrm{OH}^{-} \text {(Haber-Weiss reaction) }
\end{aligned}
$$

These results suggest the possible contribution of released iron free radicals from ischemic placenta in preeclampsia to its etiology ${ }^{(5)}$.

Excess iron can react with free radical produced from cell membrane that is polyunsaturated fatty acids and circulating lipoproteins initiates lipid peroxidation and damaged placenta is a site for release of free radicals in preeclampsia ${ }^{(11)}$. So elevated serum iron and decreased total iron binding capacity may play an important role in the pathogenesis of preeclampsia.

\section{Conclusion}

We concluded the high level of serum iron may be associated with preeclampsia. Along with serum iron and TIBC estimation of other parameters such as ferritin and transferrin may be useful for the measurement of maternal iron status.

\section{References}

1. Uzma Shamsi, Sarah Saleem, Noureen Nishter. Epidemiology and risk factors of preeclampsia; an overview of observational studies. Al Ameen J Med Sc i 2013; 6(4):292-300.

2. Jennifer Uzan, Marie Carbonnel, Olivier Piconne, Roland Asmar, Jean-Marc Ayoubi. Pre-eclampsia: pathophysiology, diagnosis, and management. Vascular
Health and Risk Management 2011:7 467474.

3. Rana M Hameed, Wasan Gh. Aboud. Total iron binding capacity (TIBC), free iron, ceruloplasmin, transferrin and ferritin concentration in pregnant women with preeclampsia. Magazin of Al-Kufa University for Biology 2013;5(2):1-7.

4. A P Moholkar, M P Bankar, K N Pujari, S $P$ Jadkar. Serum calcium and magnesium levels in preeclampsia. Serum calcium and magnesium levels in preeclampsia. International Journal of Pharmacy and Biological Sciences Jul-Sept 2014; 4(3):42-45.

5. Dr. Tasneem Zafar, Dr Zafar Iqbal. Iron status in preeclampsia. Professional Medical journal Mar 2008; 15(1):74-80.

6. Tietz NW "Text book of clinical chemistry 2nd edition "Tietz NW (Ed) WB Saunders Company Philadelphia 1994; 2059

7. Cao G, Prior R L. Clinical Chemistry Anthocyanins and iron metabolism in human serum 1999b; 574-76.

8. National committee for Clinical Laboratory Standards User Evaluation of precision performance of clinical chemistry devices. NCCLS. 1984 NCCLS publication EPS-T. 
9. Shakuntala Masti, Dattatreya K. Study of serum iron and total iron binding capacity in preeclampsia. International journal of pharmacy and Biological Sciences Jan Mar 2014; 4(1):69-74.

10. Rahab Mohamed Osman, Gad Allah Modawe, Abd Elkarim A. Abdrabo. Assessment of iron status in pregnant ladies with preeclampsia. International journal of Research in Pharmacy and Biosciences Feb 2015; 2(2): 8-11.

11. Sabitha Kandi, Sudhakar T, C Venugopal, Rajkumar, Md Rafi, K V Ramana. Preeclampsia and iron status: a review. American journal of Medical and Biological Research 2014; 2(6):121-123.

12. Hulya A, Seyithan T, Konca A, Ebubekir B, Nuri B, Yakup K. Antioxidant potential and transferrin, ceruloplasmin and lipid peroxidation levels in women with preeclampsia. Journal of Investigative Medicine 2003; 51(5): 284-287.

13. K N Pujari, S P Jadkar. Superoxide dismutase levels in leukemias. International journal of Basic Medical Sciences July 2011; 2(2):96-100.

14. D M Vasudevan, Sreekumari S, Kannan Vaidyanathan. Free radicals and antioxidants: in Textbook of Biochemistry for medical students 7 th edition, published by Jaypee brothers 2013, p 433-438. 